少，大分子盐类的稳定作用还是相当高的. 例如, 图中曲线 2 是含有一 $\mathrm{COOH}$ 为 0.2 毫 克当量/克的大分子铅盐，而曲线 3 是 用含 有一 $\mathrm{COOH}$ 为 2.52 毫克当量/克的硬脂酸 铅，郎前者比后者含的羧基铅盐小十多倍. 因此，从这里可知，在接枝大分子中所含的 铅盐比低分子中所含的铅盐对聚氯乙烯具有 大得多的稳定作用. 关于此种接枝型大分子 增韧-稳定剂的合成动力学和结构与性 能关
系及其对一些高聚物的增韧一稳定作 用，作 者将另行报导.

\section{参考 交 献}

[1] Braun, D., Ebrahim, A., Langbein, G., Kunststoff, 54, [3], 147 (1964).

[2] 曾汉民、张维邦、陈伟烈, 中山大学学报 (自然科 学 ), No.2, 226 (1964).

[3] 賏汉民、张维邦, 高分子通讯, 7，34（1965）.

[4] Turley, S. G., J. Polymer Sci., C1, No. 1, 101 (1963).

[5] 賏汉民、冯允公, 科学通报, 7, 642(1965).

\title{
化. 学
}

\section{鈧 的 重 量 法 測 定 以苯基乙酸作試剂}

\author{
林长山王順荣梁树权
}

(中国科学技术大学) (中国科学院化学研究所)

茶基乙酸已用于针和铟的测定．鉴于针 和镜常常可用同一有机试剂在不同酸度的介 质中沉淀 ${ }^{[1,2]}$ ，而达到分离和测定之目的，因 此试用苯基乙酸作锌的沉淀剂. 主要的结果 是苯基乙酸能从 $\mathrm{pH} 4-6.5$ 的介质中定量沉 淀锌，而铀在 $\mathrm{pH} 2.2^{[3]}$ 和 $\mathrm{pH} 2.8$ 或以上 ${ }^{[4]}$ 定量沉腚. 试剂用量是锌的 35 倍, 郎能定 量沉淀，郎使加到约 90 倍亦无害. 镜量为 0.4-19 毫克（郎 0.6 - 29 毫克氧化镜）均 能测定 (大于 19 毫克未试验)。沉淀系苯 基乙酸锌，其分子式经元素分析证实为 $\mathrm{Sc}\left(\mathrm{C}_{6} \mathrm{H}_{5} \mathrm{CH}_{2} \mathrm{COO}\right)_{3}$. 沉淀的热分解曲线上,
值到 $140^{\circ} \mathrm{C}$ 有一本台, $650-900^{\circ} \mathrm{C}$ 有另一 平台（代表氧化锌）。说明此沉淀 可以干燥 $\left(120^{\circ} \mathrm{C}\right)$ 称重, 或灼烧为氧化锁称重. 全交将在最近期內另行发表.

\section{參考文 献}

[1] 梁树权、洪水皆,化学学报, 28, 12, 100,139(1962).

[2] Alimarin, I. P. and Shen Han-Si, Talanta, 9, 1 (1962).

[3] Purushottam, A. and Rao, Bh. S.V.R., Z. Anal. Chem. 141, 97 (1954).

[4] Datta, S. K. and Banerjee, G., Anal. Chim. Acta, 12, 38 (1955). 